\title{
O cuidado de enfermagem em Estomaterapia e o uso das tecnologias
}

\author{
Nursing care in Stomatherapy and the use of technologies \\ El cuidado de enfermería en Estomaterapia y el uso de las tecnologías
}

\author{
Shino Shoji ${ }^{1}$, Norma Valéria Dantas de Oliveira Souza², Vanessa Cristina Maurício³, \\ Carolina Cabral Pereira da Costa ${ }^{4}$ Fabiano Teixeira Alves ${ }^{5}$
}

\begin{abstract}
RESUMO
O objetivo deste estudo é discutir a aplicabilidade das tecnologias do cuidado em saúde e enfermagem no contexto da assistência em Estomaterapia. Trata-se de um estudo de revisão integrativa da literatura, realizada na Biblioteca Virtual em Saúde, de janeiro a março de 2015, que selecionou dez publicações, das quais três abordam as tecnologias na assistência em estomaterapia e as demais (sete) aludem às tecnologias do cuidado em saúde e enfermagem de forma ampla, não se evidenciando um foco de aplicação. Essas publicações definem conceitos e explicitam os tipos de tecnologias mais utilizados. Assim, a discussão em torno das tecnologias de cuidado se faz relevante, pois a assistência em Estomaterapia está estreitamente vinculada à adequada utilização dessas tecnologias. Considera-se que o sucesso do cuidado em Estomaterapia advém da aplicação harmônica das formas de tecnologias do cuidado, as quais se mostram essenciais para a plena recuperação da clientela.
\end{abstract}

DESCRITORES: Cuidados de enfermagem. Tecnologia biomédica. Estomaterapia.

\begin{abstract}
This study aimed at discussing the applicability of health care and nursing technologies in the context of care in Stomatherapy. This is an integrative review, carried out in the Virtual Health Library, in the period from January to March 2015, that selected ten publications. It was found that three articles brought information on Stomatherapy care technologies and the others (seven) made allusion to technologies in health care and nursing, without noticing a focus of use. These publications define concepts and explain the types of the most commonly used technologies. Thus, the discussion about the technologies of care is relevant, because the assistance in Stomatherapy is closely associated with the proper use of these technologies. It is considered that the success of care in Stomatherapy comes from the harmonious joint application of all forms of care technologies available, which are essential for the full recovery of the clientele.
\end{abstract}

DESCRIPTORS: Nursing care. Biomedical technology. Stomatherapy.

\footnotetext{
${ }^{1}$ Hospital Universitário Clementino Fraga Filho da Universidade Federal do Rio de Janeiro (UFRJ) - Rio de Janeiro (RJ), Brasil.

${ }^{2}$ Faculdade de Enfermagem da Universidade do Estado do Rio de Janeiro (UERJ) - Rio de Janeiro (RJ), Brasil.

${ }^{3}$ Instituto Nacional de Traumatologia e Ortopedia (INTO) do Ministério da Saúde - Rio de Janeiro (RJ), Brasil.

${ }^{4}$ Faculdade de Enfermagem da Universidade do Estado do Rio de Janeiro (UERJ) - Rio de Janeiro (RJ), Brasil.

${ }^{5}$ DOMINUS CARE serviços em saúde - Rio de Janeiro (RJ), Brasil.

Endereço para correspondência: Shino Shoji - Boulevard 28 de setembro, 157 - Vila Isabel - CEP: 20551-030 - Rio de Janeiro (RJ), Brasil -

E-mail: shinoshoji@gmail.com

Artigo recebido em: 18/01/2015. Aceito para publicação em: 19/07/2016.
} 


\section{RESUMEN}

Ese estudio tiene como objetivo discutir la aplicabilidad de las tecnologías de asistencia sanitaria y enfermería en el contexto de Estomaterapia. Revisión integradora, celebrada en la Biblioteca Virtual en Salud, en el período de enero a marzo de 2015, que seleccionó diez publicaciones. Se encontró que tres artículos trajeron información sobre las tecnologías en asistencia en Estomaterapia y los otros (siete) hicieron alusión a las tecnologías en asistencia en salud y enfermería de forma amplia, sin subrayar un foco de aplicación. Esas publicaciones definen conceptos y explican los tipos de tecnologías más comúnmente utilizadas. Resulta que la discusión alrededor de las tecnologías de cuidado es relevante, porque la asistencia en Estomaterapia está estrechamente relacionada con el uso adecuado de las tecnologías. Se considera que el éxito de la atención en Estomaterapia proviene de la armonía y la aplicación conjunta de todas las formas de tecnologías disponibles, ya que son esenciales para la recuperación completa de la clientela.

DESCRIPTORES: Atención de enfermería. Tecnología biomédica. Estomaterapia.

\section{INTRODUÇÃO}

Este estudo trata das tecnologias do cuidado em saúde e Enfermagem aplicadas à assistência em Estomaterapia.

A Estomaterapia, especialidade exclusiva do enfermeiro, foca o cuidado a pessoas estomizadas, com lesões de pele e com incontinência anal e/ou urinária. Logo, a especialidade constrói e utiliza um conhecimento extenso e, consequentemente, presta cuidados abrangentes, o que exige um profissional qualificado, adequadamente habilitado e competente ${ }^{1}$.

O uso da tecnologia permeia a história da humanidade, pois acompanha as civilizações desde o momento em que passa a desenvolver técnicas para facilitar suas atividades de vida diária. Desse modo, o arsenal tecnológico representa um conjunto de atividades associadas a símbolos, instrumentos e máquinas, visando à construção de obras e fabricação de produtos, segundo teorias, métodos e processos ${ }^{2}$.

Assim como o conceito de cuidado, existem várias acepções para definir tecnologia. Pela etimologia, "tecno" vem do grego techné, referindo-se ao saber fazer, e "logia" advém do sufixo, também grego, logos, significando razão. Desse modo, entende-se que tecnologia se refere à razão do saber fazer. Sua definição também remonta a um conjunto de ações, entre as quais se incluem métodos, procedimentos, técnicas, equipamentos e outros instrumentos, aplicados com conhecimento científico, envolvendo diversos saberes e habilidades ${ }^{3}$.

A tecnologia é um processo que abarca diversificadas dimensões, do qual resulta um produto, que pode ser um bem durável, uma teoria, uma nova maneira de fazer algo. Desse modo, articulam-se saberes e habilidades que necessariamente não precisam resultar em um equipamento ou um aparelho tecnológico ${ }^{4}$.
Nessa perspectiva, compreende-se que a tecnologia não representa apenas produtos palpáveis, mas também pode se apresentar como um trabalho que envolve ações concretas e abstratas, ações essas que buscam alguma finalidade, entre as quais se destaca, para nossos objetivos, o cuidado em saúde e em Enfermagem. Aqui, entende-se que a Enfermagem representa esferas objetivas e subjetivas, englobando desde o desenvolvimento de técnicas e procedimentos até a sensibilidade, a criatividade e a empatia ${ }^{3,4}$.

Salienta-se, então, que tecnologia em saúde e em Enfermagem também se caracteriza em conhecimentos e instrumentos imateriais que, interligados, fundamentam e delimitam as diversas maneiras de cuidar. Nesse sentido, a tecnologia pode se apresentar como uma medição da racionalidade e da subjetividade humana, fortalecendo e qualificando o cuidado ${ }^{5}$. Assim, o uso da tecnologia tem como finalidade principal tornar cada vez mais eficiente a atividade humana que, direta e/ou indiretamente, está a serviço do cuidado ${ }^{6,7}$.

$\mathrm{Na}$ Enfermagem, a tecnologia gera impacto significativo no processo de trabalho, sendo designada como a aplicação dos conhecimentos científicos de modo sistemático no auxílio para melhor atender ao ser humano. É importante destacar ainda que o uso da tecnologia não deve ser entendido como paradigma de cuidado contrário ao indivíduo, e sim como fator de humanização, até mesmo nos ambientes mais tecnologicamente intensos de cuidados ${ }^{6,8}$.

Essas tecnologias aplicadas no trabalho em saúde classificam-se em:

- leves - as relações do tipo produção de vínculo, acolhimento, gestão como uma forma de governar processos laborais;

- leve-duras - saberes estruturados que operam no processo de trabalho em saúde, como a clínica médica, a clínica psicanalítica e a epidemiologia; 
- duras - material concreto, como máquinas, normas e estruturas organizacionais ${ }^{5,7,8}$.

O cuidado de Enfermagem e as tecnologias estão integrados, uma vez que tal profissão está comprometida com princípios, leis e teorias, e essas tecnologias consistem na expressão do conhecimento científico e em sua própria transformação. Os conhecimentos de Enfermagem elaborados e/ou aprimorados são classificados e estruturados segundo seu grau de abstração. A estrutura do conhecimento pode ser definida em metaparadigma, filosofia, modelos conceituais, teorias e indicadores empíricos ${ }^{9}$.

Por meio dessas definições, verifica-se que, em especial, o cuidado em Estomaterapia utiliza todos os tipos de tecnologias. Por exemplo, em relação às tecnologias duras, citam-se as coberturas para lesões de pele, os equipamentos coletores e adjuvantes para o cuidado com estomas e com a pele periestoma. Em relação às tecnologias leve-duras, pode-se mencionar a maneira pela qual o enfermeiro utiliza e transmite o conhecimento necessário acerca do uso desses equipamentos, coberturas e dos exercícios para viabilizar a melhora da pessoa com incontinência. Já o cuidado humanizado, que perpassa por um bom relacionamento interpessoal entre profissional e usuário, pode ser um exemplo de tecnologia leve.

Essas três categorias de tecnologia estão inter-relacionadas e fazem parte do processo de cuidar/cuidado, exigindo que, nos serviços de saúde, essas diversas tecnologias sejam constantemente avaliadas e utilizadas para satisfazer às necessidades dos usuários ${ }^{10}$. No entanto, o uso das tecnologias, apesar dos benefícios, vem gerando indagações no que concerne aos possíveis impactos, aos riscos e às relações que se estabelecem entre os sujeitos envolvidos no processo de cuidado. Essas indagações e inquietações apontam para a necessidade de se refletir e promover discussões que possam utilizar as tecnologias com eficiência e eficácia em prol de um cuidado de excelência.

A partir dessa contextualização, seleciona-se a seguinte questão de pesquisa: o que há publicado sobre o uso das tecnologias em saúde e Enfermagem aplicadas à assistência em Estomaterapia? Com isso, objetiva-se discutir a aplicabilidade das tecnologias do cuidado em saúde e Enfermagem no contexto da assistência em Estomaterapia.

Este estudo é relevante para a Enfermagem em Estomaterapia, pois contribui para a capacitação dos enfermeiros especialistas, uma vez que, devido ao número crescente de pessoas estomizadas, com lesões de pele de múltiplas naturezas e também devido ao elevado índice de pessoas com algum tipo e grau de incontinência, faz-se necessária a formação de profissionais instrumentalizados para utilizar as tecnologias a favor do bem-estar dessas pessoas ${ }^{11}$. Sendo assim, cada vez mais essa especialidade da Enfermagem utilizará tecnologias diversas para cuidar com competência, além de viabilizar um processo de reflexão sobre seu cotidiano profissional, passando a fundamentar sua atividade laboral.

\section{MÉTODOS}

Este é um estudo descritivo e do tipo revisão integrativa da literatura (RIL). Esse tipo de estudo contempla a síntese do conhecimento e permite uma compreensão completa do fenômeno analisado, viabilizando, assim, a definição de conceitos, a revisão de teorias e evidências, a análise de problemas metodológicos, o desenvolvimento de políticas, a construção de protocolos e procedimentos. Ademais, a RIL oferece subsídios para o desenvolvimento do pensamento crítico, a fim de contribuir com o funcionamento da prática diária na assistência direta ao paciente ${ }^{12}$. A RIL divide-se em seis fases, a saber:

1. formulação da pergunta norteadora, considerada a principal fase desse método, pois, a partir dela, definem-se pontos fundamentais do trabalho, como a determinação dos participantes, as intervenções a serem avaliadas e os resultados a serem mensurados;

2. busca ou amostragem na literatura, que deve ocorrer sequencialmente à formulação da questão norteadora, consistindo na organização do método da busca dos dados;

3. coleta de dados, que acontece após a seleção do material a ser utilizado, seguida de análise dos dados, que deverão ser organizados por meio de um instrumento previamente elaborado;

4. análise crítica dos estudos incluídos, quando se extraem conteúdos dos materiais previamente separados e realiza-se uma análise crítica do que foi descrito;

5. discussão dos resultados, fase na qual o material encontrado e anteriormente discutido é comparado, e, por fim;

6. apresentação da revisão integrativa ${ }^{12}$.

Foram avaliadas as produções científicas indexadas nas seguintes bases de dados eletrônicas: Literatura Internacional em Ciências da Saúde (MEDLINE), Biblioteca Virtual em Saúde (BVS), Literatura Latino-Americana e do Caribe em Ciências da Saúde (LILACS), Índice Bibliográfico Español en Ciencias de la Salud (IBECS), Base de Dados de Enfermagem (BDENF) e Scientific Electronic Library Online (SciELO). 
O procedimento de coleta das publicações foi realizado entre janeiro e março de 2015. As publicações foram captadas a partir dos unitermos: Estomaterapia e tecnologias do cuidado. Utilizando-se esses unitermos, não se obteve sucesso na captação de produção científica sobre o objeto.

Desse modo, optou-se por realizar uma pesquisa apenas com as palavras-chave estomaterapia e cuidados de Enfermagem; e, posteriormente, com as palavras-chave tecnologias do cuidado e enfermagem. Nesse procedimento, não se restringiu idioma e nem se delimitou recorte temporal. Foram considerados para o estudo apenas artigos científicos disponibilizados na íntegra e de domínio público em versão on-line.

Após o mapeamento dos dados, foram selecionados dez artigos, que estavam em conformidade com a questão de pesquisa e seus objetivos e que atenderam aos critérios de inclusão da pesquisa.
O registro da análise inicial dos artigos foi realizado em instrumento contendo os seguintes aspectos: base de dados, ano de publicação, título, objetivo do estudo, desenho metodológico e principais resultados. Após seleção e organização dos artigos, empregou-se a análise temática, que possibilita interpretar e agrupar os dados semelhantes. Desse agrupamento, emergiu a seguinte categoria: o uso das tecnologias do cuidado e a assistência em Estomaterapia, que é apresentada posteriormente.

\section{RESULTADOS}

As principais características das publicações captadas são apresentadas no Quadro 1, no qual se explicita a base de dados de onde foram coletados os artigos, os descritores utilizados, o ano de publicação, os periódicos nos quais os

Quadro 1. Características dos artigos integrados na análise bibliográfica.

\begin{tabular}{|c|c|c|c|c|c|c|}
\hline $\begin{array}{l}\text { Base } \\
\text { de dados }\end{array}$ & Descritores & $\begin{array}{c}\text { Ano de } \\
\text { publicação }\end{array}$ & Fonte & Título & $\begin{array}{l}\text { Objeto } \\
\text { do estudo }\end{array}$ & $\begin{array}{c}\text { Tipo } \\
\text { de estudo }\end{array}$ \\
\hline $\begin{array}{l}\text { BVS/ } \\
\text { LILACS }\end{array}$ & $\begin{array}{l}\text { Cuidados de } \\
\text { Enfermagem; } \\
\text { estomia; ido- } \\
\text { so; classifica- } \\
\text { ção interna- } \\
\text { cional de fun- } \\
\text { cionalidade; } \\
\text { incapacidade } \\
\text { e saúde }\end{array}$ & 2014 & $\begin{array}{l}\text { Revista Bra- } \\
\text { sileira de En- } \\
\text { fermagem }\end{array}$ & $\begin{array}{c}\text { Ações } \\
\text { ecossistêmicas } \\
\text { e gerontotecno- } \\
\text { lógicas no } \\
\text { cuidado de } \\
\text { Enfermagem } \\
\text { complexo } \\
\text { ao idoso } \\
\text { estomizado }\end{array}$ & $\begin{array}{l}\text { Ações ecos- } \\
\text { sistêmicas e } \\
\text { gerontotecno- } \\
\text { lógicas e cui- } \\
\text { dados de En- } \\
\text { fermagem em } \\
\text { Estomaterapia }\end{array}$ & $\begin{array}{l}\text { Descritivo e } \\
\text { qualitativo }\end{array}$ \\
\hline $\begin{array}{l}\text { BVS/ } \\
\text { LILACS }\end{array}$ & $\begin{array}{l}\text { Úlcera varico- } \\
\text { sa; cuidados } \\
\text { de Enferma- } \\
\text { gem; pesquisa } \\
\text { qualitativa }\end{array}$ & 2009 & $\begin{array}{l}\text { Revista Bra- } \\
\text { sileira de En- } \\
\text { fermagem }\end{array}$ & $\begin{array}{l}\text { Enfermagem } \\
\text { em Estomate- } \\
\text { rapia: cuidados } \\
\text { clínicos ao por- } \\
\text { tador de úlcera } \\
\text { venosa }^{14}\end{array}$ & $\begin{array}{l}\text { Cuidados de } \\
\text { Enfermagem } \\
\text { a clientes com } \\
\text { úlcera venosa }\end{array}$ & $\begin{array}{l}\text { Revisão bi- } \\
\text { bliográfica; } \\
\text { qualitativa }\end{array}$ \\
\hline $\begin{array}{l}\text { BVS/ } \\
\text { LILACS }\end{array}$ & $\begin{array}{l}\text { Tecnologia } \\
\text { biomédica; } \\
\text { unidades } \\
\text { de terapia } \\
\text { intensiva; } \\
\text { Enfermagem; } \\
\text { Enfermagem } \\
\text { fundamental }\end{array}$ & 2014 & $\begin{array}{l}\text { Revista Bra- } \\
\text { sileira de En- } \\
\text { fermagem }\end{array}$ & $\begin{array}{l}\text { Tecnologia no } \\
\text { cuidado de } \\
\text { Enfermagem: } \\
\text { uma análise a } \\
\text { partir do marco } \\
\text { conceitual da } \\
\text { Enfermagem } \\
\text { fundamental }\end{array}$ & $\begin{array}{c}\text { Tecnologias } \\
\text { no âmbito da } \\
\text { saúde e Enfer- } \\
\text { magem }\end{array}$ & $\begin{array}{c}\text { Campo; } \\
\text { descritiva; } \\
\text { qualitativa; } \\
\text { etnográfica }\end{array}$ \\
\hline $\begin{array}{l}\text { BVS/ } \\
\text { LILACS }\end{array}$ & $\begin{array}{l}\text { Conhecimento; } \\
\text { tecnologia; } \\
\text { Enfermagem }\end{array}$ & 2008 & $\begin{array}{l}\text { Revista Bra- } \\
\text { sileira de En- } \\
\text { fermagem }\end{array}$ & $\begin{array}{l}\text { Cuidado e tec- } \\
\text { nologia: aproxi- } \\
\text { mação através } \\
\text { do modelo de } \\
\text { cuidado }\end{array}$ & $\begin{array}{l}\text { Reflexão do } \\
\text { cuidado na } \\
\text { perspectiva da } \\
\text { tecnologia }\end{array}$ & Reflexão \\
\hline
\end{tabular}


Quadro 1. Continuação.

\begin{tabular}{|c|c|c|c|c|c|c|}
\hline $\begin{array}{l}\text { Base } \\
\text { de dados }\end{array}$ & Descritores & $\begin{array}{c}\text { Ano de } \\
\text { publicação }\end{array}$ & Fonte & Título & $\begin{array}{c}\text { Objeto } \\
\text { do estudo }\end{array}$ & $\begin{array}{c}\text { Tipo } \\
\text { de estudo }\end{array}$ \\
\hline $\begin{array}{l}\text { BVS/ } \\
\text { LILACS }\end{array}$ & $\begin{array}{l}\text { Cuidados de } \\
\text { Enfermagem; } \\
\text { organização } \\
\text { e administra- } \\
\text { ção; serviços } \\
\text { de Enferma- } \\
\text { gem; admi- } \\
\text { nistração de } \\
\text { serviços de } \\
\text { saúde }\end{array}$ & 2005 & $\begin{array}{c}\text { Revista } \\
\text { Brasileira de } \\
\text { Enfermagem }\end{array}$ & $\begin{array}{l}\text { Acolhimento: } \\
\text { tecnologia leve } \\
\text { nos processos } \\
\text { gerenciais do } \\
\text { enfermeiro }^{15}\end{array}$ & $\begin{array}{c}\text { Tecnologias } \\
\text { leves no } \\
\text { processo } \\
\text { gerencial dos } \\
\text { enfermeiros }\end{array}$ & $\begin{array}{l}\text { Estudo de } \\
\text { caso; quali- } \\
\text { tativa }\end{array}$ \\
\hline $\begin{array}{l}\text { BVS/ } \\
\text { LILACS }\end{array}$ & $\begin{array}{l}\text { Enfermagem } \\
\text { hospitalar; } \\
\text { cuidado de } \\
\text { Enfermagem; } \\
\text { tecnologia; } \\
\text { humanização }\end{array}$ & 2008 & $\begin{array}{c}\text { Escola } \\
\text { Anna Nery } \\
\text { Revista de } \\
\text { Enfermagem }\end{array}$ & $\begin{array}{l}\text { Tecnologias } \\
\text { leves em } \\
\text { saúde e sua } \\
\text { relação com } \\
\text { o cuidado de } \\
\text { Enfermagem } \\
\text { hospitalar }{ }^{16}\end{array}$ & $\begin{array}{c}\text { A incorporação } \\
\text { de tecnologias } \\
\text { leves no } \\
\text { contexto } \\
\text { hospitalar, } \\
\text { na ótica de } \\
\text { enfermeiras, } \\
\text { e sua relação } \\
\text { com o cuidado } \\
\text { de Enfermagem }\end{array}$ & $\begin{array}{l}\text { Descritiva- } \\
\text {-explorató- } \\
\text { ria; qualita- } \\
\quad \text { tiva }\end{array}$ \\
\hline $\begin{array}{l}\text { BVS/ } \\
\text { LILACS }\end{array}$ & $\begin{array}{l}\text { Tecnologia } \\
\text { da informa- } \\
\text { ção; saúde; } \\
\text { Enfermagem; } \\
\text { cuidados de } \\
\text { Enfermagem; } \\
\text { serviços de } \\
\text { Enfermagem }\end{array}$ & 2010 & $\begin{array}{c}\text { Revista Texto } \\
\text { e Contexto } \\
\text { Enfermagem }\end{array}$ & $\begin{array}{l}\text { Cuidado huma- } \\
\text { no e tecnologia } \\
\text { na Enferma- } \\
\text { gem contem- } \\
\text { porânea e } \\
\text { complexa }{ }^{17}\end{array}$ & $\begin{array}{l}\text { Cuidado huma- } \\
\text { no, tecnologias } \\
\text { da informação } \\
\text { e o pensamen- } \\
\text { to complexo } \\
\text { no cenário con- } \\
\text { temporâneo da } \\
\text { Enfermagem }\end{array}$ & Reflexão \\
\hline $\begin{array}{l}\text { BVS/ } \\
\text { BDENF }\end{array}$ & $\begin{array}{l}\text { Desenvol- } \\
\text { vimento } \\
\text { tecnológico; } \\
\text { cuidados de } \\
\text { Enfermagem; } \\
\text { atenção } \\
\text { primária à } \\
\text { saúde; cicatri- } \\
\text { zação }\end{array}$ & 2013 & $\begin{array}{c}\text { Revista de } \\
\text { Enfermagem } \\
\text { da Universi- } \\
\text { dade Federal } \\
\text { de Santa } \\
\text { Maria }\end{array}$ & $\begin{array}{c}\text { Assistência de } \\
\text { Enfermagem a } \\
\text { portadores de } \\
\text { feridas: tecno- } \\
\text { logias de cuida- } \\
\text { do desenvolvi- } \\
\text { das na atenção } \\
\text { primária18 }\end{array}$ & $\begin{array}{l}\text { Tecnologias do } \\
\text { cuidado em } \\
\text { Enfermagem } \\
\text { e portadores } \\
\text { de ferida }\end{array}$ & $\begin{array}{l}\text { Explorató- } \\
\text { ria/qualita- } \\
\text { tiva }\end{array}$ \\
\hline $\begin{array}{l}\text { BVS/ } \\
\text { BDENF }\end{array}$ & $\begin{array}{l}\text { Enfermagem; } \\
\text { tecnologia; } \\
\text { conhecimento }\end{array}$ & 2012 & $\begin{array}{c}\text { Revista de } \\
\text { Enfermagem } \\
\text { da Universi- } \\
\text { dade Federal } \\
\text { de Santa } \\
\text { Maria }\end{array}$ & $\begin{array}{l}\text { Tecnologias } \\
\text { inovadoras do } \\
\text { cuidado em } \\
\text { Enfermagem }\end{array}$ & $\begin{array}{c}\text { Tecnologia } \\
\text { no campo } \\
\text { do saber em } \\
\text { Enfermagem }\end{array}$ & Reflexão \\
\hline $\begin{array}{l}\text { BVS/ } \\
\text { LILACS }\end{array}$ & $\begin{array}{c}\text { Ética; } \\
\text { tecnologia; } \\
\text { conhecimento; } \\
\text { saúde; } \\
\text { Enfermagem }\end{array}$ & 2006 & $\begin{array}{c}\text { Revista Texto } \\
\text { e Contexto } \\
\text { Enfermagem }\end{array}$ & $\begin{array}{l}\text { Tecnologias de } \\
\text { cuidado em } \\
\text { saúde e Enfer- } \\
\text { magem e suas } \\
\text { perspectivas } \\
\text { filosóficas }^{19}\end{array}$ & $\begin{array}{l}\text { Tecnologia } \\
\text { de cuidado } \\
\text { em saúde e } \\
\text { Enfermagem }\end{array}$ & Reflexão \\
\hline
\end{tabular}

BVS: Biblioteca Virtual em Saúde; LILACS: Literatura Latino-Americana e do Caribe em Ciências da Saúde; BDENF: Base de Dados de Enfermagem. 
artigos foram divulgados, o título da obra, o objeto de estudo e o tipo de metodologia adotada.

A temática prevalente nos artigos utilizados são as tecnologias do cuidado em Enfermagem (90\%), e apenas um (10\%) trata especificamente dos cuidados de Enfermagem em Estomaterapia. Ademais, dois dos artigos que abordam as tecnologias do cuidado em Enfermagem também relacionam o tema com a assistência em Estomaterapia.

Todos os artigos estão disponibilizados na íntegra, nas bases de dados eletrônicas pesquisadas: oito (80\%) na BVS/ LILACS e dois (20\%) na BVS/BDENF. Os oito artigos encontrados na BVS/LILACS estão publicados nas seguintes fontes: cinco (50\%) na Revista Brasileira de Enfermagem; dois (20\%) na Revista Texto e Contexto Enfermagem; e dois (10\%) na Escola Anna Nery Revista de Enfermagem.

Dos 24 descritores e palavras-chave utilizados nos artigos, a maioria são: cuidados de Enfermagem (25,0\%); Enfermagem (20,8\%) e tecnologia (16,7\%). As publicações datam de 2005 a 2014, e todas estão vinculadas à área de saúde e Enfermagem. Em relação ao tipo de estudo, 40\% são artigos de reflexão e $60 \%$, pesquisa qualitativa.

Os artigos captados abordam as tecnologias leves, leve-duras e duras que devem ser utilizadas pelos enfermeiros estomaterapeutas no atendimento à clientela assistida ${ }^{3,8,15-17,20-22}$. Algumas publicações reforçam que a abordagem não deve compreender apenas ações voltadas para recuperação fisiológica dos clientes, nem apenas para o uso das tecnologias duras, mas incluir outras dimensões da vida humana, como o lazer,o trabalho, a vida sexual, entre outras ${ }^{14,18,19}$. Os autores salientam que os aspectos psicossociais das pessoas necessitadas dos cuidados de Enfermagem em Estomaterapia devem ser amplamente abordados, correlacionando-se as três categorias de tecnologia a fim de se oferecer um atendimento holístico e integral aos indivíduos ${ }^{4,13}$.

\section{DISCUSSÃO}

\section{As tecnologias do cuidado e a assistência em Estomaterapia}

As tecnologias do cuidado estão disponíveis para auxiliar os profissionais de saúde e enfermeiros no atendimento integral à clientela assistida; apropriar-se dessas tecnologias e desenvolver novas oportunidades para a Enfermagem implementar e aperfeiçoar o cuidado, mediante o compromisso da qualidade ${ }^{17,23}$.
Os estomaterapeutas procuram continuamente ferramentas que possam auxiliá-los em suas ações cotidianas e no cuidar que a Enfermagem deve oferecer. $\mathrm{O}$ uso das tecnologias objetiva melhorar a qualidade da assistência prestada à clientela, aliando a teoria à prática. $\mathrm{O}$ enfermeiro estomaterapeuta atua no planejamento, na execução e na avaliação da assistência de Enfermagem, utilizando uma metodologia assistencial que abrange prevenção, diagnóstico e tratamento da clientela. Para isso, esse profissional emprega as diversas categorias de tecnologias do cuidado disponíveis ${ }^{14}$.

$\mathrm{O}$ enfermeiro estomaterapeuta conta com inúmeras tecnologias duras disponíveis no mercado, as quais devem ser utilizadas a partir da avaliação do profissional frente à situação de cada cliente. No entanto, há de se ter uma análise crítica sobre elas, pois a indicação e a aplicação dessas tecnologias devem levar em consideração não apenas as características das lesões e do produto disponibilizado, mas também as condições da manutenção do tratamento, tendo em vista que algumas delas não são distribuídas gratuitamente e seus custos apresentam-se elevados ${ }^{18,24}$.

Aprofundando essa discussão, é necessário se atentar para os avanços tecnológicos e para o crescimento da biotecnologia e da engenharia genética nos serviços de saúde, buscando o respeito aos preceitos éticos e técnicos das práticas clínicas ${ }^{2,19}$ : "o estomaterapeuta deve assumir e liderar o cuidar holístico e interdisciplinar com qualidade diferenciada e custo-utilidade comprovada, tendo como fundamentos os conhecimentos prático, estético, étnico, empírico e sociopolítico, constantemente atualizados e baseados em evidências/resultados, e voltado para uma clientela diversa em suas necessidades, porém única na sua humanidade" 25 .

A tecnologia dura pode ser representada pelo material concreto, como equipamentos tecnológicos (hardware), mobiliário permanente ou de consumo, normas, rotinas e estruturas organizacionais ${ }^{26}$. Esse tipo de tecnologia do cuidado representa as inovações na área de Estomaterapia, dentre as quais pode-se citar as inúmeras coberturas produzidas por diversas empresas e utilizadas tanto em feridas nos variados estágios de cicatrização e nas complicações desse processo cicatricial quanto nos equipamentos coletores e adjuvantes dispensados aos clientes estomizados, destacando-se o sistema de irrigação e oclusor, o qual facilita seu processo de reabilitação. Essas tecnologias estão presentes também no tratamento 
da incontinência urinária, tanto em sua forma cirúrgica quanto por meio de exercício.

Se, por um lado, o desenvolvimento tecnológico constante amplia o campo de atuação do profissional e alarga as possibilidades de bem-estar da clientela, por outro, pode repercutir negativamente na prática diária, caso o enfermeiro não o domine plenamente, não leve em consideração o custo-benefício ou encare a tecnologia dura como única alternativa de tratamento ou o fito de seu cuidado, desumanizando-o $\mathrm{O}^{8,18,26}$.

A partir desta análise, compreende-se que as tecnologias vão além das inovações técnicas relacionadas a produtos e maquinários; elas também abrangem as relações humanas e o processo de cuidado, que vai desde a elaboração e o planejamento prévio do plano de cuidados de Enfermagem até sua aplicação e finalização. Além disso, gerenciamento, coordenação e elaboração de pesquisas também são considerados tecnologias do cuidado.

Corroborando esse entendimento, alguns autores ${ }^{3-8}$ afirmam que a totalidade das tecnologias abrange não somente os produtos artificiais fabricados pela humanidade, mas também os processos de produção, envolvendo máquinas e recursos necessários em um sistema sociotécnico de fabricação. Ademais, engloba igualmente as metodologias, as competências, as capacidades e os conhecimentos necessários para realizar tarefas produtivas, adicionados ao próprio uso dos produtos colocados dentro do contexto sociocultural.

Para os mesmos autores ${ }^{3-8}$, o desenvolvimento de novas tecnologias, sejam produtos, artefatos ou sistemas de informação e comunicação, constitui um dos fatores-chave para compreender e explicar todas as transformações que se processam em nossa sociedade. Dessa maneira, podemos dizer que a tecnologia está intrinsecamente associada aos valores humanos.

As tecnologias leves, consideradas como do campo das relações humanas, são de extrema importância para o sucesso terapêutico no contexto da Estomaterapia, pois o vínculo e o acolhimento realizados pelo profissional com a clientela determinarão os laços de confiança entre eles, facilitando a adesão ao tratamento. Nesse sentido, o ser humano, para conseguir adaptar-se a sua condição de saúde-doença, necessita das tecnologias de relações denominadas "leves": produção de comunicação, acolhimento, vínculos, empatia, criatividade, autonomização ${ }^{16,27}$. O grande compromisso e desafio de quem gerencia o cuidado é o de utilizar as relações enquanto tecnologia, no sentido de edificar um cotidiano, por intermédio da construção mútua entre os sujeitos. E, por meio dessas mesmas relações, dar sustentação à satisfação das necessidades dos indivíduos e os valorizar (trabalhadores e usuários) como potentes para intervirem na concretização do cuidado ${ }^{13,15}$.

A interação enfermeiro-cliente é essencial para o favorecimento da ação terapêutica, principalmente em Estomaterapia, pois os indivíduos podem necessitar de cuidados por um tempo prolongado ${ }^{15,28}$.É essencial, então, que o estomaterapeuta faça com que o cliente participe efetivamente desse cuidado e esteja apto a realizá-lo de forma contínua e independente; para tanto, o estomaterapeuta se vale de sua empatia, criatividade e acolhimento para ajudar essa pessoa a ser partícipe do processo de cuidar/cuidado, utilizando com maior predominância as tecnologias leves produzidas pela profissão e áreas afins ${ }^{16,24}$.

$\mathrm{O}$ acolhimento ocorre por um conjunto de ações construídas na relação com o outro, além do fornecimento de um ambiente agradável, que traga conforto e bem-estar ao cliente $^{15}$. $\mathrm{O}$ enfermeiro estomaterapeuta deve minimizar a frieza de locais estigmatizados, como os hospitais e os consultórios, e propiciar um local facilitador para as relações humanas. Nesse sentido, a aplicação correta, atualizada e habilidosa das tecnologias será uma importante ferramenta para facilitar a adesão ao tratamento e conferir bem-estar a essa clientela.

Ainda no campo das tecnologias leves do cuidado, é muito importante o ensino ao autocuidado aos clientes, o qual se inicia com a avaliação do estomaterapeuta sobre a capacidade dos indivíduos exercerem determinadas ações. Eles são avaliados de acordo com sua capacidade intelectual, física, motora, cognitiva e emocional. Caso os clientes possuam algum déficit para adesão às atividades de autocuidado, o profissional busca, juntamente com o cliente, alternativas para suplantar tal circunstância, além de contar com a colaboração de cuidadores e familiares ${ }^{29}$.

O essencial é que esses sujeitos saibam proteger o estoma e cuidar adequadamente de suas lesões e de seus estomas; os pacientes devem ainda aprender a detectar possíveis complicações. As tecnologias leves mostram-se fundamentais nesse tipo de cuidado, pois a profissão valoriza as relações humanas e o conhecimento técnico-científico para uma assistência de qualidade. 
As tecnologias leve-duras referem-se aos saberes profissionais que, se bem estruturados, auxiliam na organização do processo de trabalho ${ }^{18,30}$. Logo, representam a forma como o profissional aplica seu conhecimento para produzir o cuidado, ou seja, essas tecnologias compreendem a busca de capacitação e informações sobre como conduzir determinada tarefa.

É essencial destacar que o modelo assistencial para a saúde é historicamente centrado nas tecnologias duras e leve-duras, tendo em vista os interesses corporativos na área gerados por grandes grupos econômicos. Logo, o cuidado à saúde tornou-se organizado num fluxo que incentiva a consulta médica, em que "o saber médico estrutura o trabalho de todos os outros profissionais, ficando a produção do cuidado dependente de tecnologias duras e leve-duras" 30 .

A realização do cuidado é centrada em um núcleo tecnológico composto de "trabalho morto", que engloba os instrumentos, e "trabalho vivo", que indica o trabalho em ato, representado pelo campo das tecnologias leves ${ }^{30}$. Evidentemente, a correlação entre eles é necessária para o cuidado em saúde, visto que os avanços tecnológicos são criados para melhorar a saúde e a qualidade de vida dos indivíduos. Porém, não se pode deixar que esses avanços tecnológicos se destinem apenas aos lucros para as grandes empresas, devem objetivar a melhoria do processo de cuidado.

O modelo assistencial que se advoga deve ofertar todos os recursos tecnológicos disponíveis aos usuários; porém, o processo de trabalho deve manter em seu núcleo o trabalho vivo, representado pelas tecnologias leves, pelo campo das relações interpessoais e subjetivas, assegurando, assim, um vínculo direto entre profissional e usuário, vínculo esse que sustente tanto o princípio da integralidade assistencial quanto a operação das linhas de cuidado. Para tudo isso, são necessários profissionais cada vez mais qualificados ${ }^{30}$.

Logo, a discussão em torno das tecnologias de cuidado faz-se relevante, pois a assistência em Estomaterapia está estreitamente vinculada à adequada utilização dessas tecnologias. Nesse sentido, outra questão importante é que os cursos de especialização em Enfermagem em Estomaterapia devem abordar em seus currículos tanto questões referentes às tecnologias duras, leve-duras e leves, quanto à sua utilização, tais como: classificação, tipos e maneiras e momentos corretos de utilização, a fim de possibilitar uma visão mais alargada e mais consciente sobre a atuação profissional especializada.

\section{CONCLUSÃO}

O cuidado em Estomaterapia está intimamente relacionado ao uso de três categorias das tecnologias do cuidado em saúde. Nesse sentido, o enfermeiro estomaterapeuta, por atender uma clientela que demanda o apoio não só físico, mas também psicossocial, utiliza inúmeras alternativas de cuidados para prestar assistência adequada a esses indivíduos.

É fundamental, então, que o estomaterapeuta identifique a importância da utilização de todas as categorias de tecnologias do cuidado em saúde a serem empregadas em sua área de atuação e saiba utilizá-las de maneira adequada. Por conseguinte, ele deve estar atento para que as inovações tecnológicas duras e leve-duras não superem, nem sejam mais valorizadas, do que as relações humanas éticas, situadas no campo das tecnologias leves. Logo, o estomaterapeuta não deve atuar como mero utilizador de coberturas e produtos destinados à clientela, mas como profissional especializado, humanizado, conhecedor dos aspectos biopsicossociais afetados nos indivíduos que serão por ele cuidados.

Portanto, o sucesso do cuidado em estomaterapia advém da harmonia e da aplicação conjunta de todas as formas de tecnologias do cuidado disponíveis, pois essas se mostram essenciais para a plena recuperação da clientela.

A escassez de artigos que correlacionem a assistência em Estomaterapia às tecnologias do cuidado evidencia a lacuna na publicação de estudos sobre a temática. Reforça-se que o uso das tecnologias está intimamente relacionado ao cotidiano da equipe de Enfermagem e, consequentemente, dos estomaterapeutas, que utilizam as diversas categorias tecnológicas em seus ambientes de trabalho e cuidados prestados à clientela assistida.

Entende-se que este estudo pode contribuir para a divulgação da temática, ampliando o quantitativo de publicações na área e auxiliando os enfermeiros estomaterapeutas a identificarem e utilizarem corretamente as tecnologias envolvidas nos cuidados à clientela. Sugere-se que novos estudos sejam realizados para divulgação e fortalecimento da temática e da especialidade de Estomaterapia. 


\section{REFERÊNCIAS}

1. Costa CPM, Squarcina DF, Paula MA. O especialista em Estomaterapia. In: Estomaterapia em foco e o cuidado especializado. São Caetano do Sul: Yendis; 2014. p. 1-12.

2. Muraro RM. Os avanços tecnológicos e o futuro da humanidade: querendo ser Deus? Petrópolis: Vozes; 2009.

3. Nietsche EA, Lima MG, Rodrigues MG, Teixeira JA, Oliveira BN, Motta CA, et al. Tecnologias inovadoras do cuidado em enfermagem. Rev Enferm UFSM. 2012;2(1):182-9.

4. Rocha PK, Prado ML, Wal ML, Carraro TE. Cuidado e tecnologia: aproximações através do modelo de cuidado. Rev Bras Enferm. 2008;61(1):113-6.

5. Liedke DC. Uso da bota de Unna como tecnologia no cuidado de enfermagem em úlcera venosa [dissertação de mestrado]. Curitiba: Universidade Federal do Paraná; 2014.

6. Martins CR, Dal Sasso GT. Tecnologia: definições e reflexões para a prática em saúde e enfermagem. Texto Contexto Enferm. 2008;17(1):11-2.

7. Thofehrn MB, Montesinos MJ, Arrieira IC, Ávila VC, Vasques TC, Farias ID. Processo de trabalho dos enfermeiros em um hospital da Espanha: ênfase nas tecnologias de cuidado. Cogitare Enferm. 2014;19(1):141-6.

8. Silva RC, Ferreira MA. Tecnologia no cuidado de enfermagem: uma análise a partir do marco conceitual da Enfermagem Fundamental. Rev Bras Enferm. 2014;67(1):111-8.

9. Fawcett J. Knowledge contemporary nursing: analysis and evolution of nursing models and theories. Philadelphia: F.A. Davos Company; 2005.

10. Schwonke CR, Lunardi Filho WD, Lunardi VL, Santos SS, Barlem EL. Perspectivas filosóficas do uso da tecnologia no cuidado de enfermagem em terapia intensiva. Rev Bras Enferm. 2011;64(1):189-92.

11. Paula MA, Santos VL. O significado de ser especialista para o enfermeiro estomaterapeuta. Rev Latino-Am Enferm. 2003;11(4):474-82.

12. Souza MT, Silva MD, Carvalho R. Revisão integrativa: o que é e como fazer. Einstein. 2010;8(1 Pt 1):102-6.

13. Dantas DV, Torres GV, Dantas RA. Assistência aos portadores de feridas: caracterização dos protocolos existentes no Brasil. Ciênc Cuid Saúde. 2011;10(2):366-72.

14. Busanello J, Silva FM, Sehnem GD, Poll MA, Deus LM, Bohlke TS. Assistência de enfermagem a portadores de feridas: tecnologias de cuidado desenvolvidas na atenção primária. Rev Enferm UFSM. 2013;3(1):175-84.

15. Mauricio VC. A pessoa estomizada e o processo de inclusão no trabalho: contribuição para enfermagem [dissertação de mestrado]. Rio de Janeiro: Universidade do Estado do Rio de Janeiro; 2011.

16. Silva $L$, Lopes $M H$. Incontinência urinária em mulheres: razões da não procura por tratamento. Rev Esc Enferm USP. 2009;43(1):72-8.
17. Ratliff CR, Haugen $\mathrm{V}$. Selecting a tool for assessing healthrelated quality of life in ostomates. J Wound Ostomy Continence Nurs. 2013;40(5):462-7.

18. Baggio MA, Erdmann AL, Dal Sasso GT. Cuidado humano e a tecnologia na enfermagem contemporânea e complexa. Texto Contexto Enferm. 2010;19(2):378-85.

19. Silva RC, Ferreira MA. A tecnologia em saúde: uma perspectiva psicossociológica aplicada ao cuidado de enfermagem. Esc Anna Nery Rev Enferm. 2009;13(1): 169-73.

20. Silva FA, Freitas CHA, Jorge MS, Moreira TM, Alcântara MC. Enfermagem em estomaterapia: cuidados clínicos ao portador de úlceras venosas. Rev Bras Enferm. 2009;62(6):889-93.

21. Koerich MS, Backes DS, Scortegagna HM, Wall ML, Veronese AM, Zeferuno MT, et al. Tecnologias de cuidado em saúde e enfermagem e suas perspectivas filosóficas. Texto Contexto Enferm. 2006;15(Esp):178-85.

22. Santos VL. Cuidados avançados em estomaterapia: vislumbrando o terceiro milênio. Rev ESc Enf USP. 1999;33(Esp):1-3.

23. Gonçalves RB. Tecnologia e organização social das práticas de saúde: características tecnológicas do processo de trabalho na rede estadual de centros de saúde de São Paulo. São Paulo: Hucitec; 1999. 278p.

24. Merhy EE. Em busca do tempo perdido: a micropolítica do trabalho vivo em saúde. In: Merhy EE, Onocko, R. Práxis em salud um desafio para lo público. São Paulo: Hucitec; 1997. p. 2-78.

25. Silva DC, Alvim NA, Figueiredo PA. Tecnologias leves em saúde e sua relação com o cuidado de enfermagem hospitalar. Esc Anna Nery Rev Enferm. 2008;12(2): 291-8.

26. Rossi FR, Lima MA. Acolhimento: tecnologia leve nos processos gerenciais do enfermeiro. Rev Bras Enferm. 2005;58(3):305-10.

27. Barros EJ, Santos SS, Gomes GC, Erdmann AL, Pelzer MT, Gautério DP. Ações ecossistêmicas e gerontotecnológicas no cuidado de enfermagem complexo ao idoso estomizado. Rev Bras Enferm. 2014;67(1):91-6.

28. Silva DF, Santos FH. O desafio do autocuidado para pacientes oncológicos estomizados. Rev Estima. 2014;12(2):28-34.

29. Mauricio VC, Souza NV. Care planning for the client bearing infection at surgery site: getting ready for self-care. R Pesq Cuid Fundam Online. 2011;3(1): 1562-71.

30. Merhy EE, Franco TB. Por uma composição técnica do trabalho centrada no campo relacional e nas tecnologias leves. Saúde Debate. 2003;27(65). 